\title{
Comparing face to face, tutor led discussion and online discussion in the classroom
}

\author{
Connie S. L. Ng and Wing Sum Cheung \\ Nanyang Technological University, Singapore
}

This study explores the relative effectiveness of in class online discussion and face to face, tutor led discussion in preservice teachers' recall of concepts. Two groups of preservice teachers, who engaged in different discussion modes, were tested two weeks later on how many concepts they could recall. No significant difference in the recall score was found between the two groups, but the group involved with the in-class discussions using a threaded discussion tool achieved a slightly higher mean score in the recall of multimedia design concepts. The online group completed a survey questionnaire on their perception of their use of online discussion. The majority perceived that they learned more online. The preservice teachers also indicated the mode of discussions that they preferred and the reasons for their choice. Half preferred to participate in in-class online discussions, rather than face to face, tutor led discussion, during class time. The findings suggested that educators and learners may choose either in-class online discussion or face to face, tutor led discussion without fear of significant disadvantages to learning.

\section{Introduction}

Online discussion is being used increasingly in higher education institutions (Wang, 2005), but most studies on computer conferencing systems in education focus only upon asynchronous online discussion (Hrastinski, 2005). There are relatively few studies concerned with the use of online discussion in the classroom setting (Chen \& Looi, 2007) and there is a need for further research on what we describe as "in-class online discussion".

Our study aims to contribute to the scant literature on in-class online discussion by exploring whether engaging pre-service teachers in in-class online discussion assists them to recall the concepts that they have learnt, compared to participating in face to face, tutor led discussion. This study involves two groups of preservice teachers. One group engaged in face to face, tutor led discussions, while another group participated in a in-class 
discussion using a threaded discussion tool during tutorial time. The second group completed a survey on their perceived use of online discussion. Their preferred mode of discussions in the classroom and the reasons for their preference were also assessed. Selected participants from the in-class online discussion group also gave feedback about the use of inclass online discussion via email.

\section{Learning through discussions}

In the past 30 years, educational theory and research has seen a shift from a behaviourist approach to a social constructivist view of learning, which emphasises the individual's construction of knowledge through collaboration in groups. The key to the social constructivist perspective of learning is learner-learner interaction, which provides scope for the social negotiation of meaning and construction of knowledge between learners connected to each other (Romiszowski \& Mason, 2004). The emphasis upon the social constructivist approach in learning has led to renewed interest in the role of discussion in learning, as evidenced by research exploring the effects of discussion on learning outcomes (Gambrell, 1996). Discussion has been identified as a characteristic of effective teaching (Ramsden, 1992) and is viewed as an appropriate activity for quality learning in tutorials (Biggs, 1990).

Traditional discussion typically involves teacher-student interaction, characterised by the structure: Initiate-Respond-Evaluate. In these interactions, the teacher initiates a topic with a question and students then follow with an answer. Finally the teacher evaluates the students' response. As a consequence, students have very limited opportunity to interact with one another (Almasi, 1996). With the resurgence in the use of discussion as a teaching technique, the professional literature has moved away from the traditional view of discussion towards viewing discussion as a social environment which allows learners to collaborate in order to construct meaning (Almasi, 1996).

The online environment, offering an array of computer mediated communication (CMC) features and tools, lends itself well to the social constructivist perspective of learning, because of the "emphasis on access to resources and the extent of collaboration between students promoted through the use of discussion boards." (Romiszowski \& Mason, 2004, p.400). Though there are many definitions of CMC, in this study we adopt the definition of Romiszowski \& Mason (2004). According to these authors, $\mathrm{CMC}$ refers to the "the process by which people create, exchange, and perceive information using networked telecommunications systems that facilitate encoding, transmitting, and decoding messages" (Romiszowski \& Mason, 2004, p. 398). 
CMC technologies include asynchronous discussion tools such as emails, discussion lists, bulletin boards and computer conferencing (Romiszowski \& Mason, 2004). Asynchronous online discussion tools are valued for their greater potential in monitoring discussion because they allow for threaded discussions (Schultz, 2003). A threaded discussion is formed in the following way. A participant makes a posting on the main topic, another participant responds directly to the posting and yet another participant responds to the response. Participants also have the option of starting a new thread on other related aspects of the main topic (Horton, 2000). Threaded discussions help participants to organise and follow online conversations without getting lost in numerous unrelated postings (Schultz, 2003).

\section{Learning in an online environment}

Althaus (1996) examined the academic performance of students who had face to face discussions in addition to asynchronous online discussions, and found that students who were involved in online discussions created responses that were more thoughtful, because they had more time to read and think about their responses compared to students in a face to face setting. Althaus (1996) also found that the students in the online class earned higher grades on average than the students in the traditional classroom (Christopher, Thomas \& Tallent-Runnels, 2004).

Fjermestad and Hiltz (2005) analysed 30 studies comparing face to face courses to courses using the asynchronous mode and found that in $86 \%$ of the studies, the asynchronous mode was found to be either better or equal to the traditional, face to face mode. One advantage commonly cited by participants in asynchronous online discussions was that their discussion was more in depth, because they have more time for reflection (Branon \& Essex, 2001). Asynchronous online discussion also allows all students, instead of one student at a time (as for face to face discussion) the opportunity to respond to a topic (Branon \& Essex, 2001).

On the other hand, Leasure Davis and Thievon (2000) discovered that the traditional classroom allows learners to interact directly and receive immediate feedback, hence fostering more meaningful learning experiences than those experienced in an online forum. Some researchers maintain that the face to face environment creates a more comfortable environment for a student to work with others, leading to rich information exchanges (Kim, Derry, Steinkuehler, Street \& Watson, 2000).

So far, many studies done on the online mode of learning compared the use of asynchronous online to the face to face method (Leasure et.al, 2000; Kim et.al., 2000). Other researchers such as Chen and Looi (2007) compared use 
of in-class, online discussion, and off-class online discussion. They did a study comparing the implementation of online discussion for both in and off classroom settings in a professional development course. They found that the learners engaged in deeper thinking and provided more perspectives in in-class online discussion. The in-class postings also contain higher percentage of inference skills than off-class postings (Chen \& Looi, 2007).

Very few studies have been done comparing the use of in-class, online discussion and face to face discussion. This study aims to address this gap by investigating whether participation in an in-class, online discussion helps pre-service teachers to recall multimedia design concepts better as compared to participation in a face to face, tutor led discussion. A threaded discussion tool, which is usually used for asynchronous online discussions, was used in this study. The use of such a tool for in-class, online discussion is an attempt to overcome the lack of structure and the difficulty of monitoring discussion commonly associated with existing synchronous online discussion tools, such as chat rooms. This study included a survey of participants' perception of their use of in-class online discussion, their preferred mode of discussion, and the reasons for their preference.

\section{Research questions}

The research questions for this study are as follows:

1. Is there a difference between the face to face, tutor led discussion group, and the in-class, online discussion group in assisting pre-service teachers to recall visual design principles?

2. How do pre-service teachers perceive their use of the in-class online discussions?

3. Do pre-service teachers prefer to participate in in-class, online discussion, or face to face, tutor led discussion during class time? What are the reasons for their preference?

\section{Methodology}

\section{Subjects}

A total of 43 pre-service teachers from two tutorial groups were involved in this study. They were taking a 13-week module named "Instructional Technology" as a compulsory component of their pre-service teacher education course, during which they were taught visual design principles in one of the tutorial sessions. Convenience sampling was used in this study. This study is best described as a quasi-experimental study as the pre-service teachers were randomly assigned to the tutorial groups by the 
coordinator of the module rather than by the researcher of this study. The face to face, tutor led group consisted of 21 pre-service teachers, while the in-class, online discussion group comprised 22 pre-service teachers. All the pre-service teachers were graduates with basic degrees and had some experience in online discussions. Both groups have more than $75 \%$ female pre-service teachers compared to male pre-service teachers.

\section{Procedure}

This study was carried out during the fifth tutorial session of the "Instructional Technology" module. In session four, the pre-service teachers from both groups were asked to read the visual design chapter from the text book. This chapter on basic design principles is easy to read and contains many examples and non-examples to illustrate the principles. During fifth tutorial session, the tutor spent 15 minutes at the start of the session to answer the pre-service teachers' queries about the chapter. This was done for both groups. After the clarification, both groups were shown a sample of a multimedia project created using PowerPoint and asked to critique the project. The project had six PowerPoint slides. Both groups spent 40 minutes on the discussion.

For one group, the tutor led a face-to-face discussion. The tutor spent the first 10 minutes eliciting from the pre-service teachers the problems that they have identified. Then, the tutor moved on to ask the pre-service teachers to offer solutions to the problems identified. The rest are then asked if they have any comments on the solutions offered.

For the in-class, online group, the tutor asked the pre-service teachers to critique the multimedia project by using the discussion tool in Blackboard, a learning management system. Though all the pre-service teachers were in the same computer laboratory, they were asked to communicate only via the online discussion tool. The pre-service teachers were observed to follow this request during this study. Before the online discussion, the tutor created six separate online forums (i.e., one for each slide) to provide a clear structure to post ideas, questions, explanations, arguments, problems, solutions and suggestions. Figure 1 shows an example.

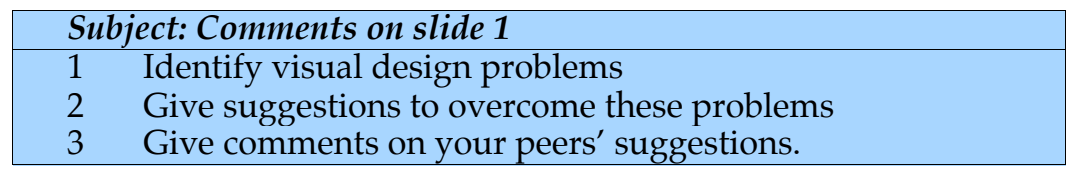

Figure 1: Discussion forum 1 (thread started by tutor)

The pre-service teachers were given an example of each of the three steps (refer to Figure 1). The pre-service teachers were told to spend the first ten 
minutes identifying problems before moving on to give suggestions to solve the identified problems. They were reminded that once someone has suggested solutions to the problems, they should start giving comments on their peers' suggestions. The pre-service teachers were free to choose any forums and the number of forums to participate in. The online discussion was purely among the pre-service teachers. The tutor was not involved in the online discussion.

Two weeks later, both groups were asked to list and describe the visual design principles. They were then scored on what they had written. In addition, a survey was administered to the in-class, online discussion group, in order to gather data on their perceptions on their use of in-class online discussion. The survey used a five-point Likert scale. The options were "Almost never", "Seldom", "Sometimes", "Often" and "Almost always". Further feedback was gathered via email from selected preservice teachers from this group, to find out their online discussion experience.

\section{Limitations of the study}

The following limitations exist for this study:

a. Only one multimedia sample was used for the critique. The choice of the sample could have an impact on the discussion and hence the learning of the pre-service teachers.

b. Convenience sampling was used and this study is best described as a quasi-experimental study, hence limited generalisations could be made from the findings in this study.

c. As this is a subject involves only two classes of pre-service teacher in Singapore, therefore the results may not be generalisable to other cultures.

d. As the study only investigated the recall of concepts, the findings may not be generalisable to other types of learning.

\section{Results and discussions}

Research question 1: Is there a difference between the face to face, tutor led discussion group and the in-class online discussion group in helping pre-service teachers to recall visual design principles?

There is no significant difference between the two groups in terms of their recall score $(\mathrm{t}=0.842 ; \mathrm{df}=41 ; \mathrm{p}>.10)$. However, responses from participants, as indicated in the survey, indicated the following advantages in getting participants to engage in in-class discussion using a threaded discussion tool. 
Persistent nature of online discussion

Text based, computer mediated communications are persistent, with the discussion messages remaining present at all times (Guzdial \& Turns, 2000). This feature may have contributed to the slightly better score. In this study, one of the survey items was "I found it useful to have written messages in the discussion forum to refer back to". Fifty-eight percent of the pre-service teachers from the in-class, online discussion group responded that they often or almost always found it useful, while $41 \%$ indicated that it was sometimes useful to be able to do so.

\section{Better focus}

Another item in the survey was "I concentrate better on the content of the posted message because of the lack of facial expressions in the discussion forum". Analysis of the response to this item showed that $55 \%$ of the preservice teachers perceived that they concentrated better on the content of the posted messages because of the lack of facial expressions in the discussion forum, while $36 \%$ responded that they sometimes concentrated better. The lack of visual and audio components of communication, instead of being a hindrance, has enabled the participants to focus upon specific tasks on hand, leading them to learn slightly more in an online environment. One of the pre-service teachers shared her view that she preferred online discussion because she can "concentrate and focus better on the discussion topics".

\section{Individual reflection}

The survey revealed that the online discussions supported individual reflection. Fifty-five percent felt that writing for discussion often or almost all the time clarified their thinking, while the remaining pre-service teachers $(45 \%)$ felt that it helped them sometimes. Higher order learning requires reflection and knowledge construction. According to Hiebert (1992) and Kilpatrick (1985), reflection is a key to conceptual change. Many teacher educators have used journal writings successfully to promote reflection and learning in pre-service teachers (e.g., Brownlee, Purdie, \& Boulton-Lewis 2001; Carter, 1998).

\section{Reflection on others' posting}

Not only did the online discussion support individual reflection more, it also helped to trigger reflection about other participants' contribution. Sixty-four percent indicated that they reflected more about their own ideas in the in-class, online discussion than they did in the face to face environment, while only $50 \%$ of them reflected more about other participants' ideas in the in-class, online discussions than when they did in a face to face environment. Hence the online environment provided opportunities for reflection by providing a forum for dialog that might not have occurred in a face to face discussion (McDuffie, 2003). The interactive 
nature of the online discussion allowed the pre-service teachers to build on others' ideas and perspectives.

To quote one of the pre-service teachers: "the online discussion facilitates greater discussion. As more and more comments are contributed, each of us gets to be exposed to more ideas thereby enriching our knowledge and understanding of the topic at hand. Not only that, we are spurred on towards higher order thinking as we are given opportunities to reflect and respond". Another pre-service teacher commented: "More time to ponder and reflect on own and other people's thoughts".

The variety of feedback from peers triggered off different threads of reflection that would have been limited in a teacher led, face to face classroom discussion. This helped the pre-service teachers to extend their reflection (McDuffie, 2003).

\section{Choice of discussion focus}

The pre-service teachers from the in-class, online discussion group could choose different aspects of visual design that they preferred to discuss, because they could join any of the discussion threads started by their peers. As result, they were not "forced" to discuss something that they were not interested in, unlike the face to face, tutor led group where the direction of the discussion was influenced by the tutor and there was only one single thread of discussion.

Knowledge building, scaffolding and motivation

According to the social constructivist perspective of learning, learners make meaning of the world by sharing with others (Kim et.al, 2000). Computer mediated communication supports this collaboration and sharing of knowledge by decentralising the distribution of ideas to the community of members (Scardamalia \& Bereiter, 1996). McLoughlin and Luca (2000) assert that peer interaction within a computer mediated environment acts as a form of scaffolding because in the progress of articulating ideas to each other, learners sharpen their own understanding.

In this study, peer interaction within a computer mediated environment did seem to have the additional advantage of motivating other participants to contribute. One of the pre-service teachers made the following comment "Through online discussion within the class, we are motivated to contribute and get involved since everyone around us is doing it".

Though the recall score for the in-class, online discussion group is not significantly higher than the face to face, tutor led discussion group, the survey revealed that pre-service teachers perceived the above advantages of in-class, online discussion. These perceived advantages may be influential in leading to similarity of scores for both groups. 
Research question 2: How do participants perceive their use of in-class, online discussions?

Three findings emerge from the survey results of the in-class online discussion group. The first one concerned the comfort level that respondents felt about sharing their comments online. The second finding revealed the pre-service teachers' perception about the worthiness of inclass online discussions. The third finding captured pre-service teachers' preferred discussion mode in the classroom and the reasons for their choice.

\section{Finding 1}

Fifty-five percent of the respondents often or almost always felt more comfortable sharing their comments in the discussion forum, compared to face to face environments, while $27 \%$ of the respondents felt so sometimes.

One of the much touted benefits of online discussion is the opportunity for shy students, who are usually silent in class, to actively participate in online conversations. The lack of social cues and norms in online communication discourages dominance of interaction by few members (Kim et al, 2000), leading to more equal participation by other members.

The pre-service teachers from the in-class, online discussion group were asked in the survey whether they prefer to participate in face to face, tutor led, or in-class, online discussions during class time. Some of those who preferred online discussion cited reasons such as less inhibition and reduced fear of humiliation. They also felt more relaxed and had more chance to share their opinions. Some of the pre-service teachers' responses are listed in Table 1.

Table 1: Pre-service teachers' reasons for their preference for in-class, online discussions

\begin{tabular}{|l|}
\hline "Allows shy ones to participate. More open and honest discussion" \\
"Fear of facial response reduced and this will minimise the fear of \\
humiliation greatly" \\
"In face to face, not everyone gets chance to speak out, online discussions \\
allows all do so" \\
\hline "Felt less inhibited and could post messages freely" \\
"Reserved, hence online discussion benefits" \\
\hline "Less pressurised" \\
\hline "F2f [face to face] - only one person can speak at one time and hence not all \\
have chance to speak. Some too shy to speak out in class" \\
"OL [online] discussion participation more relaxing and interesting and \\
can think better" \\
\hline $\begin{array}{l}\text { "[online discussion] allows opinion to be said without judgement from } \\
\text { tutors, allows freedom to respond to peer's answers online." }\end{array}$ \\
\hline
\end{tabular}


Past research has demonstrated that different cultures seemed to exhibit different patterns in their online interactions with their peers. For example, Warschauer (1997) found, in a study of Filipino, Japanese, Chinese, and Vietnamese students enrolled in an American community college, tendencies toward unequal participation across cultures, in both face to face and online discussion. His study found that Filipino students tended to dominate face to face discussions while other students, especially the Japanese, spoke less. However, when it comes to online discussions, the difference in participation across cultures was lower, for example the Japanese students participated much more actively in the online discussions. Warschauer (1997) attributed this finding to cultural factors.

For some cultures, it is a sign of respect for students not to speak to their teachers and elders unless they are asked to. Speaking out in front of the whole class, for students from such cultures, can be intimidating (Chan, 2004). This cultural factor may explain why as high as $82 \%$ of the preservice teachers in the in-class, online discussion group felt more comfortable at least sometimes, if not most of the time, about sharing their comments in the in-class, online discussion as compared to in a face to face discussion. The distance of online interaction allows participants to break the norms of cultural practice to interact just as actively as a more vocal person, who can still continue his or her own active contribution (McComb, 1993).

\section{Finding 2}

Sixty-four percent of the respondents felt that participating in the in-class, online discussion was often or almost always worth their time and effort, while $27 \%$ felt that it was sometimes worth their effort.

Thirty-two percent of the respondents revealed that they often or almost always learned more in an online discussion forum than in a face to face environment (e.g. classroom or tutorial sessions), while $50 \%$ of the respondents indicated that they felt so sometimes.

The pre-service teachers clearly perceived that they learnt more in in-class, online discussions and that participating in such discussions is worth their while and effort. Althaus (1996) claimed that improved perception of learning in online discussion is a result of the more intellectual environment offered by online discussion. Such an environment helps the participants to learn better as they are more actively and equally engaged.

\section{Finding 3}

Eighty-two percent of the participants enjoyed reading messages posted by other participants. When it came to reading feedback from other participants about their own messages, the percentage was even higher, at 
$86 \%$. However, with regard to contributing postings, only $46 \%$ enjoyed posting their ideas or opinions in the discussion forum, while $64 \%$ enjoyed responding to other participants' messages.

It is clear that the pre-service teachers enjoyed reading messages in the inclass, online forum, but a majority of them did not enjoy contributing postings. The sharp decrease in the percentages of pre-service teachers who enjoyed contributing postings is mostly likely due to the need to devote substantial time to contributing to the discussion (McDuffie, 2003). Contributing a posting to an online discussion requires not only the synthesis of the idea, but also the phrasing of the idea, and the need to "insert a note into the overall discussion structure" (Guzdial \& Turns, 2000, p. 442). The challenge in contributing a coherent and constructive posting may be difficult, especially when participants are novices in the subject domain (Guzdial \& Turns, 2000).

Research question 3: Do pre-service teachers prefer to participate in in-class online discussion or face to face, tutor led discussion during class time? What are the reasons for their preferences?

While the pre-service teachers generally perceived that they learnt more online, only $50 \%$ opted for in-class, online discussions. The reasons for their preference were highlighted in the discussion for research question 2 (refer to Table 1). The rest of the pre-service teachers indicated that they preferred face to face, tutor led discussions. These pre-service teachers cited negative feelings towards online discussion. Some of the reasons they gave are illustrated in Table 2.

Table 2: Pre-service teachers' reasons for their preference for face to face, tutor led discussions

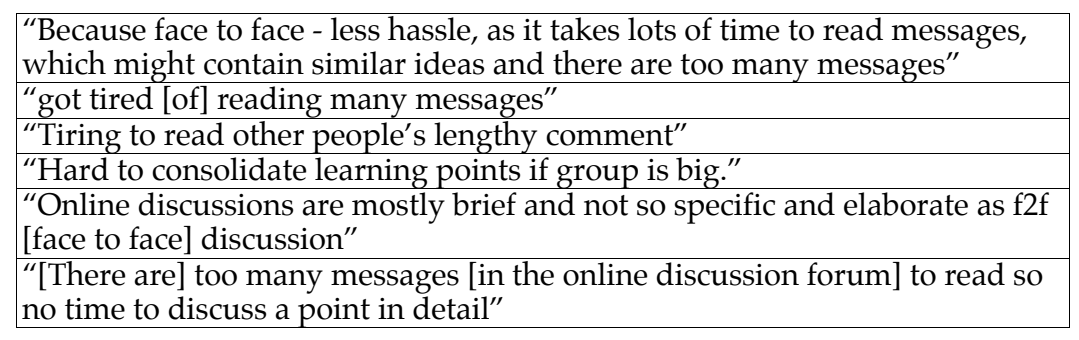

It seems that the pre-service teachers' positive perception of learning online was overshadowed by the dissatisfaction that they felt about contributing to online discussion. Though computer mediated communication shares similar language patterns with oral communication (Condon \& Cech, 1996), more structures for online discussions may need to be put in place to make the online discussions a more enjoyable experience for the learners. 
The reasons cited by the pre-service teachers, such as having to read too many messages, gave some indications on the problem areas. These negative comments about the online discussion might be overcome by establishing appropriate rules in the online environment (Table 3).

Table 3: Suggested solutions to overcome problems with in-class, online discussion

\begin{tabular}{|c|c|c|}
\hline $\begin{array}{c}\text { Problem highlighted } \\
\text { by pre-service } \\
\text { teachers }\end{array}$ & Suggested solutions & Rationale \\
\hline $\begin{array}{l}\text { " "got tired [of] } \\
\text { reading many } \\
\text { messages" } \\
\text { "[There are] too } \\
\text { many messages } \\
\text { [in the online } \\
\text { discussion forum] } \\
\text { to read so no time } \\
\text { to discuss a point } \\
\text { in detail" }\end{array}$ & $\begin{array}{l}\text { Small group online discussion } \\
\text { Break the class into smaller } \\
\text { groups for the in class online } \\
\text { discussion so that the } \\
\text { participants are not } \\
\text { overwhelmed by the } \\
\text { quantity of posting. Smaller } \\
\text { groups will naturally make } \\
\text { the number of postings more } \\
\text { manageable and minimise } \\
\text { fatigue and reduce repetition } \\
\text { of ideas }\end{array}$ & $\begin{array}{l}\text { Researchers in cooperative } \\
\text { learning fields report that } \\
\text { students working in small } \\
\text { groups tend to learn more of } \\
\text { what is taught and remember it } \\
\text { longer than if the same content } \\
\text { is presented in other instructio- } \\
\text { nal formats (Johnson, Johnson } \\
\text { \& Smith, 1991). This observa- } \\
\text { tion could be implemented in } \\
\text { the in-class, online discussion } \\
\text { environment as well. }\end{array}$ \\
\hline $\begin{array}{l}\text { "Because face to } \\
\text { face - less hassle, } \\
\text { as it takes lots of } \\
\text { time to read } \\
\text { messages, which } \\
\text { might contain } \\
\text { similar ideas and } \\
\text { there are too many } \\
\text { messages" }\end{array}$ & $\begin{array}{l}\text { Avoid repetition of ideas } \\
\text { Remind the pre-service } \\
\text { teachers not to repeat ideas } \\
\text { unless they have valuable } \\
\text { comments to add (Cheung \& } \\
\text { Hew, 2005) }\end{array}$ & $\begin{array}{l}\text { Some pre-service teachers } \\
\text { might simply post ideas to } \\
\text { increase the number of total } \\
\text { messages that they have } \\
\text { contributed. Reminding them } \\
\text { not to repeat ideas would } \\
\text { discourage these pre-service } \\
\text { teachers from simply } \\
\text { paraphrasing others' postings. }\end{array}$ \\
\hline $\begin{array}{l}\text { - "Tiring to read } \\
\text { other people's } \\
\text { lengthy comment" }\end{array}$ & $\begin{array}{l}\text { One idea per posting } \\
\text { Ask the class to include only } \\
\text { one idea per message } \\
\text { (Cheung \& Hew, 2006). }\end{array}$ & $\begin{array}{l}\text { If the pre-service teachers incl- } \\
\text { ude only one idea per posting, } \\
\text { it will help to cut down the } \\
\text { length of each posting. }\end{array}$ \\
\hline
\end{tabular}

There are many other reasons that could have influenced the pre-service teachers' preferred mode of discussion. For example, those who did not choose in-class, online discussions could have lacked the discipline required to craft well-thought out and meaningful postings.

\section{Conclusions}

The results of this study suggest that educators and students may choose either in-class, online discussion or face to face, tutor led discussion, without fear of significant disadvantages to learning. In-class, online discussion creates opportunities for more equal participation in the classroom and empowers reticent learners to contribute as equally as those 
who tend to dominate face to face interaction. Participating in in-class discussion using a threaded discussion tool also facilitates reflection, similar to the reflective thinking brought about in journal writing, while providing the additional benefit of sharing reflections with others. While these benefits are similar to the findings found in many studies comparing asynchronous online discussions with face to face environments, this study shows that these advantages could be reaped in in-class, online discussions using a threaded discussion tool as well.

The recall scores comparison shows that in-class, online discussions helped the pre-service teachers to remember visual design principles slightly, but not significantly, better. However, many of the pre-service teachers perceived that they learnt more effectively in online discussion. It is, however, not necessarily the preferred mode of discussion for some of these pre-service teachers A number of them reported being overwhelmed by the sheer tediousness of going through voluminous messages before they could contribute to the discussion. This is despite the fact that the tutor created one separate online forum for each slide of the PowerPoint sample given. More needs to be done to structure the in-class, online discussion to enhance the level of enjoyment of the pre-service teachers towards this mode of learning. Establishing ground rules for in-class, online discussion might help to overcome some of the problems faced by the pre-service teachers.

This study focused only on the recall of concepts. More research studies are needed to explore if in-class, online discussion could be used to enhance other types of learning outcome and how the experience may be made more satisfying for the participants. With the potentially richer interaction that in-class, online discussion offers in the classroom, it is "only the creativity, imagination and personal involvement of participants that constrains the potential of online discussions" (Romiszowski \& Mason, 2004, p. 398).

\section{References}

Almasi, J. F. (1996). A new view of discussion. In L. B. Gambrell \& J. F. Almasi (Eds.), Lively discussions: Fostering engaged reading (pp. 2-24). Newark, DE: International Reading Association.

Althaus, S. (1996). Computer-mediated communication in the university classroom: An experiment with on-line discussions. Communication Education, 46, 158-174.

Biggs, J. B. (1990). Teaching for quality learning at university. Buckingham: Society for Research into Higher Education and Open University Press.

Branon, R. F. \& Essex, C. (2001). Synchronous and asynchronous communication tools in distance education: A survey of instructors. TechTrends, 45, 36-42. 
Brownlee, J., Purdie, N. \& Boulton-Lewis, G. (2001). Changing epistemological beliefs in preservice teacher education students. Teaching in Higher Education, 6(2), 247-268.

Carter, C. (1998). The use of journals to promote reflection. Action in Teacher Education, 19(4), 39-42.

Chan, E. (2004). Embracing cultural diversity and enhancing students' learning environment. CDT Link, 8(3). [verified 29 Sep 2007] http: / / www.cdtl.nus.edu.sg/link/Nov2004/le.htm

Chen, W. \& Looi, C.-K. (2007). Incorporating online discussion in face to face classroom learning: A new blended learning approach. Australasian Journal of Educational Technology, 23(3), 308-327. http: / / www.ascilite.org.au/ajet/ajet23/chen.html

Cheung, W. S. \& Hew, K. F. (2005). How can we facilitate students' in-depth thinking and interaction in an asynchronous online discussion environment? A case study. Proceedings of the AECT International Convention, Orlando, FL, USA.

Cheung, W. S. \& Hew, K. F. (2006). Examining students' creative and critical thinking and student to student interactions in an asynchronous online discussion environment: A Singapore case study. Asia-Pacific Cybereducation Journal, 2(2). http:/ / acecjournal.org/current_issue/article/2_2_examining_full.php

Christopher, M. M., Thomas J. A. \& Tallent-Runnels, M. K. (2004). Raising the bar: Encouraging high level thinking in online discussion forums. Roeper Review, 26(3), 166-172.

Condon, S. L. \& Cech, C. G. (1996). Functional comparison of face-to-face and computer-mediated decision-making interactions. In S. Herring (Ed.), Computermediated communication: Linguistic, social, and cross-cultural perspectives (pp. 6580). Philadelphia: John Benjamins.

Fjermestad, J. \& Hiltz, S. R. (2005). Effectiveness for students: Comparisons of "inseat" and ALN courses. In S. R. Hiltz \& R. Goldman (Eds.), Learning together online. Mahwah, New Jersey: Lawrence Erlbaum Associates.

Gambrell, L. B. (1996). What research reveals about discussion. In L. B. Gambrell \& J. F. Almasi (Eds.), Lively discussions: Fostering engaged reading (pp. 25-38). Newark, DE: International Reading Association.

Guzdial, M. \& Turns, J. (2000). Effective discussion through a computer-mediated anchored forum. Journal of the Learning Sciences, 9(4), 437-470.

Hiebert, J. (1992). Reflection and communication: Cognitive considerations in school mathematics reform. International Journal of Educational Research, 17(5), 439-456.

Hrastinski, S. (2005). Research on computer-mediated communication in education: Summarizing the past to prepare for the future. Proceedings of the Ed-Media Conference, Montreal.

Horton, S. (2000). Web teaching guide: A practical approach to creating course web sites. New Haven, CT: Yale University Press.

Johnson, D. W., Johnson, R. T. \& Smith, K. A. (1991). Cooperative learning: Increasing college faculty instructional productivity. ASHE-FRIC Higher Education Report No.4. Washington, DC: School of Education and Human Development, George Washington University. 
Kilpatrick, J. (1985). Reflection and recursion. Educational Studies in Mathematics 16, $1-26$.

Kim, J., Derry, S. J., Steinkuehler, C. A., Street, J. P. \& Watson, J. (2000). Web-based online collaborative learning. Proceedings of AERA 2000, American Educational Research Association Annual Meeting. New Orleans, Louisiana.

Kim, K-J. \& Bonk, C. J. (2002). Cross-cultural comparisons of online collaboration. Journal of Computer-Mediated Communication, 8(1). http: / jcmc.indiana.edu/vol8/issue1/kimandbonk.html

Leasure, A. R., Davis, L. \& Thievon, A. L. (2000). Comparison of student outcomes and preferences in a traditional vs. world wide web-based baccalaureate nursing research course. Journal of Nursing Education, 29(4), 149-154.

McComb, M. (1993). Augmenting a group discussion course with computermediated communication in a small college setting. Interpersonal Computing and Technology, 1(3). [verified 29 Sep 2007] http: / / www.emoderators.com/ipct-j/1993/n3/mccomb.txt

McDuffie, A. R. \& Slavit, D. (2003). Utilizing online discussion to support reflection and challenge beliefs in elementary mathematics methods classrooms. Contemporary Issues in Technology and Teacher Education, 2(4), 446-466. http: / / www.citejournal.org/vol2/iss4/mathematics/article1.cfm

McLoughlin, C. \& Luca, J. (2000). Cognitive engagement and higher order thinking through computer conferencing: We know why but do we know how? In Flexible Futures in Tertiary Teaching. Proceedings of the 9th Annual Teaching Learning Forum, 2-4 February, Curtin University of Technology. http: / / lsn.curtin.edu.au/tlf/tlf2000/mcloughlin.html

Romiszowski, A. \& Mason, R. (2004). Computer-mediated communication. In D. H. Jonassen (Ed.), Handbook of Research for Educational Communications and Technology, 2nd Ed. (pp. 397-431). New York: Macmillan.

Ramsden, P. (1992). Learning to teach in higher education. London: Routledge.

Scardamalia, M., \& Bereiter, C. (1996). Computer support for knowledge-building communities., Mahwah NJ: Lawrence Erlbaum Associates.

Schultz, R. A. (2003). The effectiveness of online synchronous discussion. Proceedings of the Informing Science + Information Technology Joint Education Conference, Finland, [viewed 18 Dec 2005, verified 29 Sep 2007] http: / / proceedings.informingscience.org/IS2003Proceedings/docs/077Schul.pdf

Warschauer, M. (1997). Computer-mediated collaborative learning: Theory and practice. Modern Language Journal, 81(4), 470-481.

Wang, C.-H. (2005). Questioning skills facilitate online synchronous discussions. Journal of Computer Assisted Learning, 21(4), 303-313.

Connie S. L. Ng and Wing Sum Cheung, National Institute of Education, Nanyang Technological University, 1 Nanyang Walk, Singapore 637616. Email: connie.ng@nie.edu.sg,wingsum.cheung@nie.edu.sg Web: http: / / www.nie.edu.au/ 